\title{
Buinytska Oksana
}

Associate Professor, Ph.D., Head of IT in Education Laboratory

Borys Grinchenko Kyiv University, Kyiv, Ukraine

o.buinytska@kubg.edu.ua

ORCID: 0000-0002-3611-2114

\section{Hrytseliak Bohdan}

Deputy Head of IT in Education Laboratory

Borys Grinchenko Kyiv University, Kyiv, Ukraine

b.hrytseliak@kubg.edu.ua

ORCID: 0000-0003-2953-8560

\section{INTEGRATION OF INFORMATION AND EDUCATIONAL SYSTEMS IN THE UNIVERSAL EDUCATION UNIVERSITY ELECTRONIC ENVIRONMENT}

\begin{abstract}
The article is devoted to the integration of educational resources and educational and informational systems in a single information and educational environment of the university. Access to the university's information and educational environment is carried out through the additional web-site of the official portal "Information and educational environment" for authorization, which uses technology of the single sign-on point, the main element of which is the creation of a user database. Taking into account the features of the analyzed directory services and the use of the domain structure of the network organization, we have selected to create the Lightweight Directory Access Protocol (LDAP) database using the OpenLDAP open protocol. Were described the implementation of the settings for a single sign-on page using the protocol for the web CAS (Central Authentication Service). To synchronize the University's corporate email and available Google services with the LDAP database, Google Apps developed a Google Apps Directory Sync application that synchronizes the structure and all users in Google Apps. In order to synchronize the e-learning system based on the LMS Moodle, an existing appropriate module was used to authenticate users through the LDAP database. Configuring the module, synchronizing users and groups is presented in the article. Also are listed the settings specified in the LocalSettings.php file that are related to LDAP authentication with the university's wiki portal via the installed and connected LDAP authentication module. Also we described an approach to synchronizing users with the systems of scientific conferences and seminars based on the open conference system engine, which includes a module for LDAP authentication.
\end{abstract}

Keywords: information and educational environment of the university; directory databases; LDAP; synchronization; Moodle; Google Apps; Open Conference System

One of the ways to ensure quality education is to create a unified information and educational environment of the university, built on competency and personality-oriented learning approaches, and provide permanent, full-access 24/7/365 to electronic systems and resources. Studying the experience of world universities in Borys Grinchenko Kyiv University was created such informational and educational environment. Its obligatory components are availability of technologies of electronic interaction of all participants of the educational process and electronic content of educational, scientific, informational, and management directions (Morze, Buinytska, 2015). In order to combine all electronic resources into a holistic system - the information and educational environment is selected by the single sign-on technology, which provides access through a separate web-site of the official portal, taking into account the rights of access to the resources of each user (Fig.1).

The combination of electronic resources in a single system is carried out virtually, not physically, but provides users with the perception of a holistic environment (Ogneviuk et al., 2016) (Fig.2). 


\section{Borys Grinchenko Kyiv University}

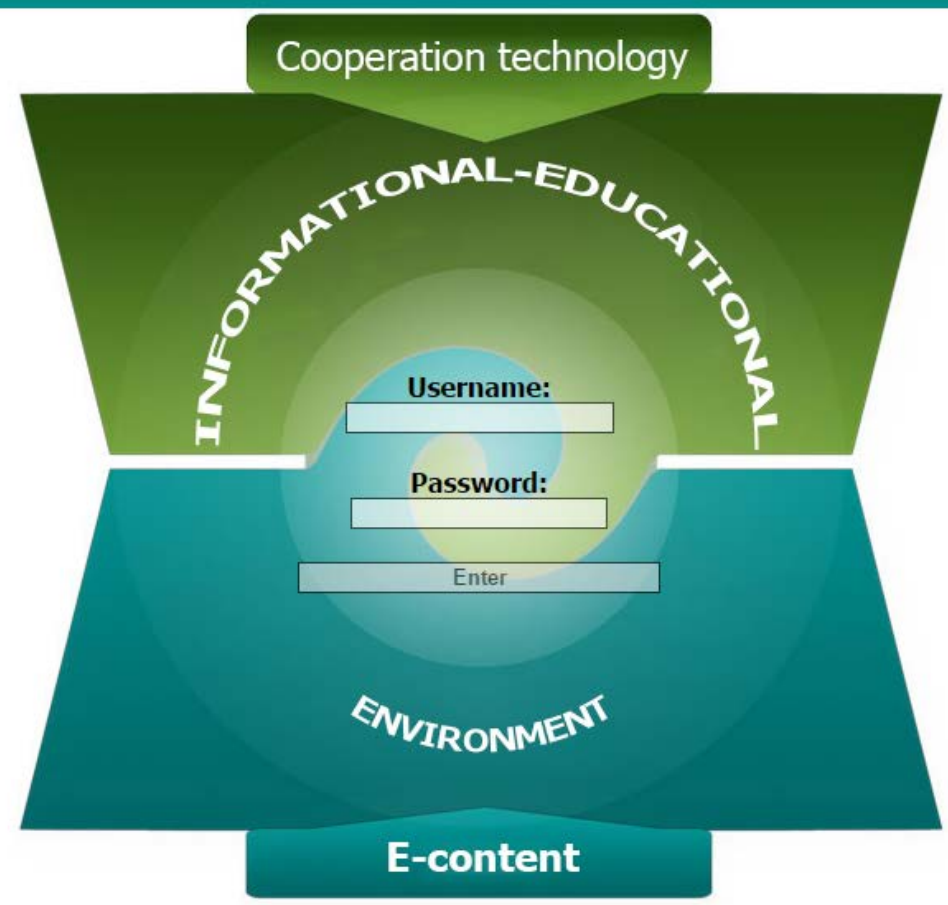

Fig.1. Webpage of Single sign-on system in Information and Educational Environment of the University

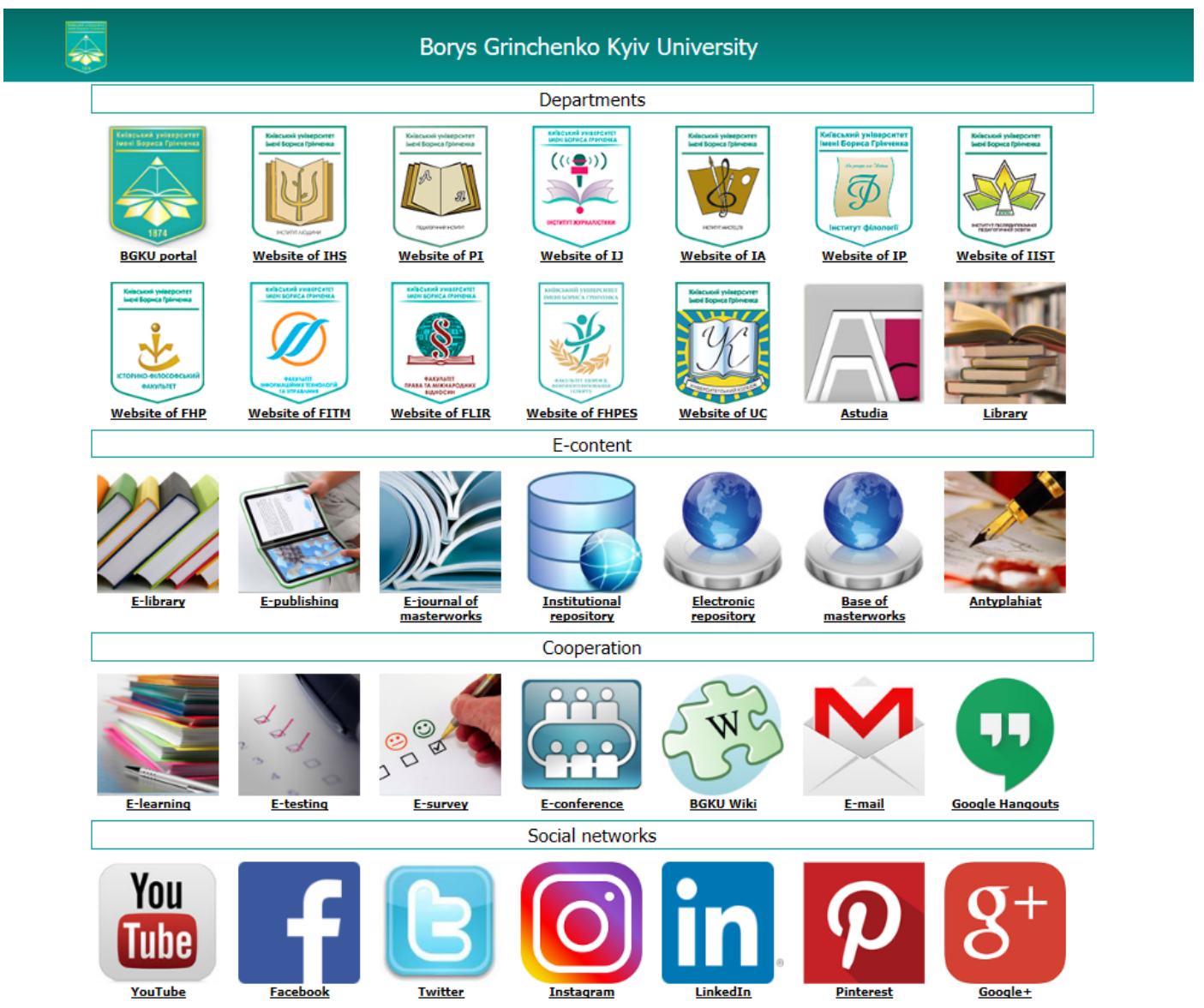

Fig.2. Webpage of access to the resources of the information and educational environment 
The main element of the single sign-on system is the user database, which will be addressed by other components of the system to verify the identity of users at the entrance to the university's information and educational environment (Oleksiuk, 2012).

To select the software to create a user database, we analyzed the free and commercial directory services (Tab.1).

Table 1.

Features of directory services

\begin{tabular}{|c|c|c|}
\hline Name & Accessibility & Characteristic features \\
\hline OpenLDAP & $\begin{array}{l}\text { Non- } \\
\text { commercial }\end{array}$ & $\begin{array}{l}\text { - the complexity of the initial settings of the } \\
\text { server; } \\
\text { - } \quad \text { cross-platform; } \\
\text { - high performance; } \\
\text { - a lot of settings; } \\
\text { - } \text { ability to use (in conjunction with Samba) for } \\
\text { a complete replacement of Windows-based } \\
\text { file servers. }\end{array}$ \\
\hline $\begin{array}{l}\text { Apache Software } \\
\text { Foundation }\end{array}$ & $\begin{array}{l}\text { Non- } \\
\text { commercial }\end{array}$ & $\begin{array}{ll}\text { - } & \text { functional separation into two independent } \\
& \text { parts; } \\
\text { - } & \text { modular server architecture; } \\
\text { - } & \text { wide support for platforms by using Java; } \\
\text { - } & \text { experimental extensions that add some } \\
\text { opportunities. }\end{array}$ \\
\hline $\begin{array}{l}\text { Novell } \\
\text { eDirectory }\end{array}$ & Commercial & $\begin{array}{ll}\text { - } & \text { cross-platform; } \\
\text { - } & \text { high speed; } \\
\text { - } & \text { reliability; } \\
\text { - } & \text { improved mechanisms for synchronizing } \\
& \text { directory data. }\end{array}$ \\
\hline $\begin{array}{l}\text { Microsoft Active } \\
\text { Directory }\end{array}$ & Commercial & 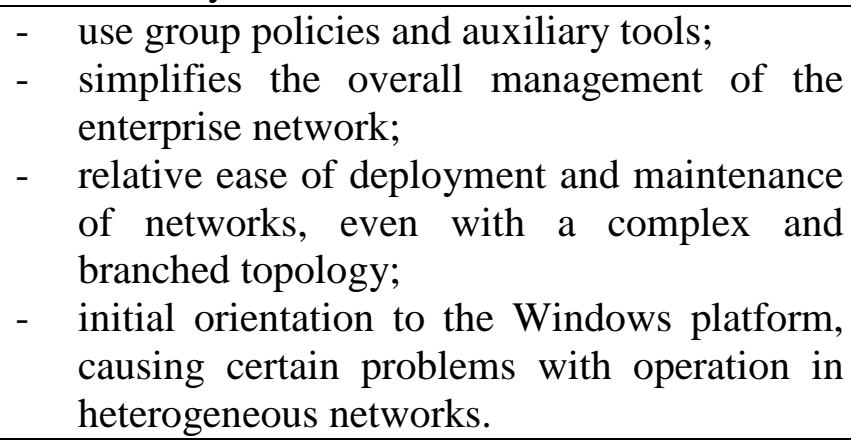 \\
\hline
\end{tabular}

Given the features of the analyzed directory services and the use of the domain structure of the network organization, it was technically easier for us to select the LDAP directory (Panov, 2017). LDAP stands for Lightweight Directory Access Protocol - that is, "easy directory access". Accordingly, the user database is created on the basis of the LDAP model using OpenLDAP software and hosted on a separate virtual server. Access to the University's database is at http://login.kubg.edu.ua.

For greater security, the transfer of information to the LDAP database is carried out through a secure protocol (ldaps://) that runs on an SSL encryption system. The authenticity of the connection is verified using a self-generated SSL certificate for the period up to February 25, 2042 (“Community developed LDAP software”, 2017). 
The database structure is based on a hierarchical principle. It includes two main branches: people and groups. The branch of the group in turn is divided into employees and students, which are also divided by the structural subdivision (Fig.3).

LDAP Account Manager has been selected as the system for managing graphical the LDAP database management system. This system allows you to work with the record tree directly, and through a convenient and flexible interface, which also has the ability to preprogramming and customizing. The system supports various authentication and expansion modules ("Authentication Plugins", 2017). For ease of operation has been made the localization of the interface into the Ukrainian language.

To log in to the administration system, you must go to the address http://login.kubg.edu.ua/lam ("Centralized authentication using OpenLDAP”, 2017). A general view of the user list is presented at (Fig.4).

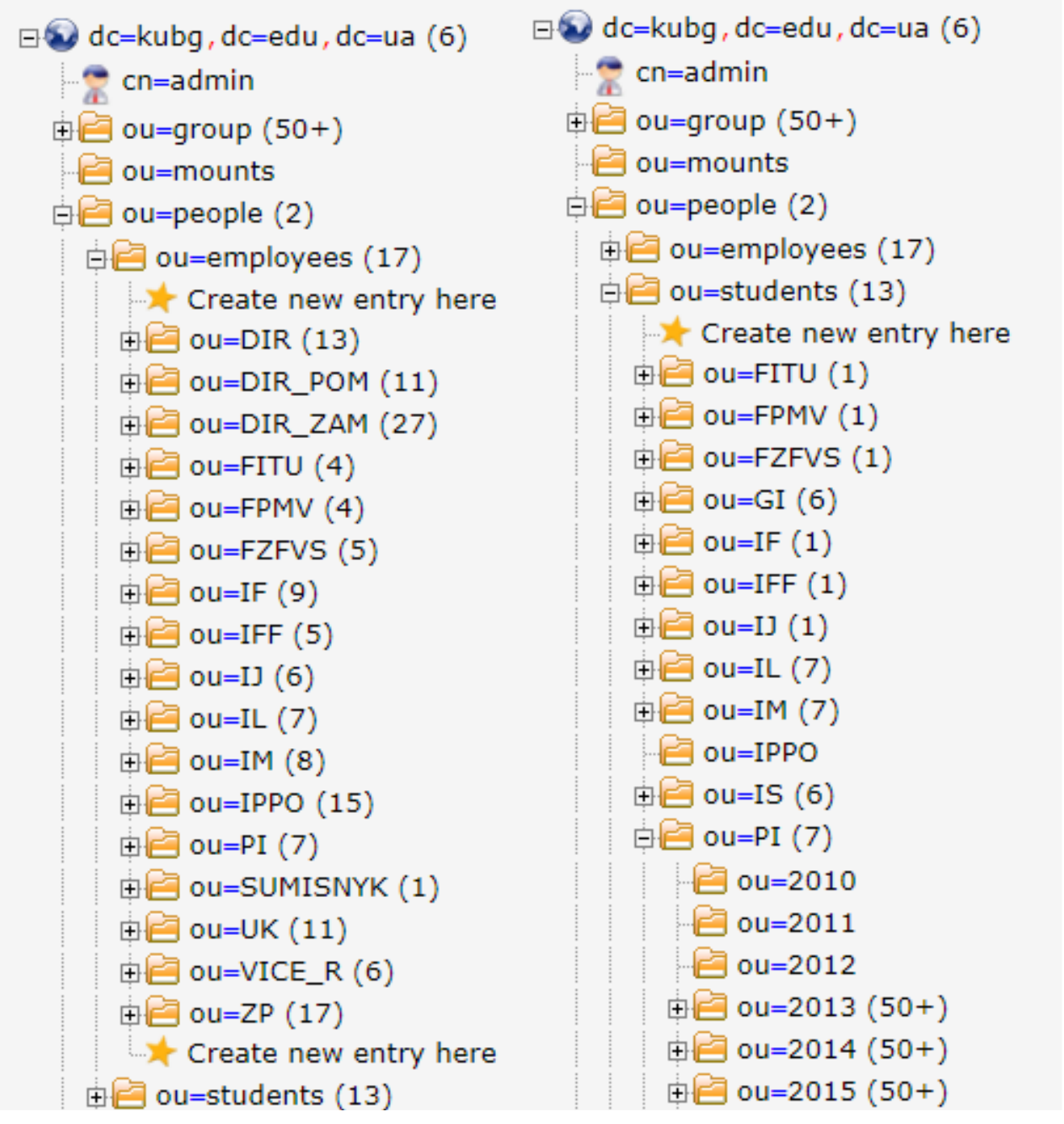

Fig.3. Database structure 


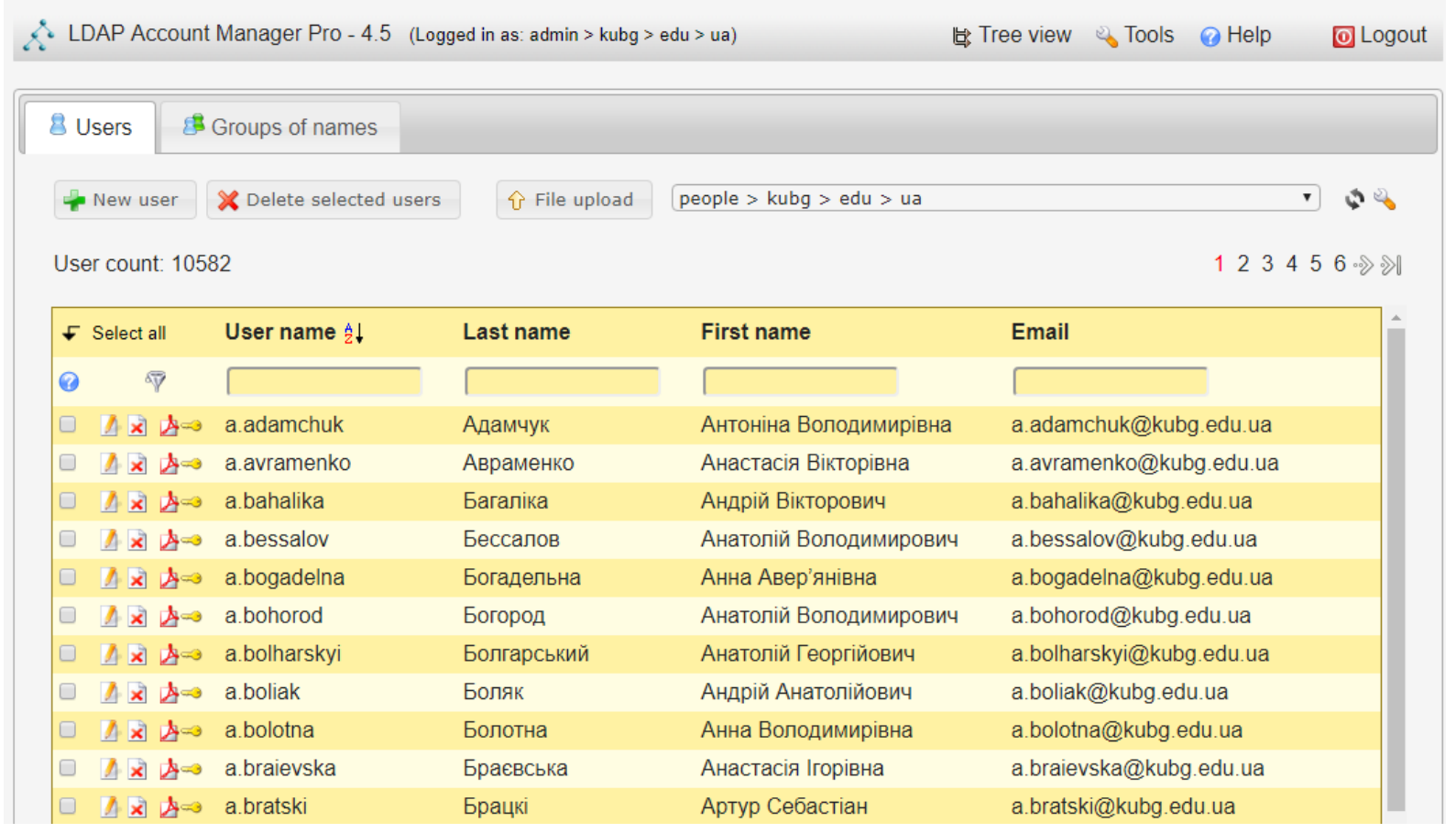

Fig.4. General view of the user list

The module Users with the initOrgPerson schema are connected to work with users. Student groups are connected to the Schema Name Group module groupOfUniqueNames (Fig.5).

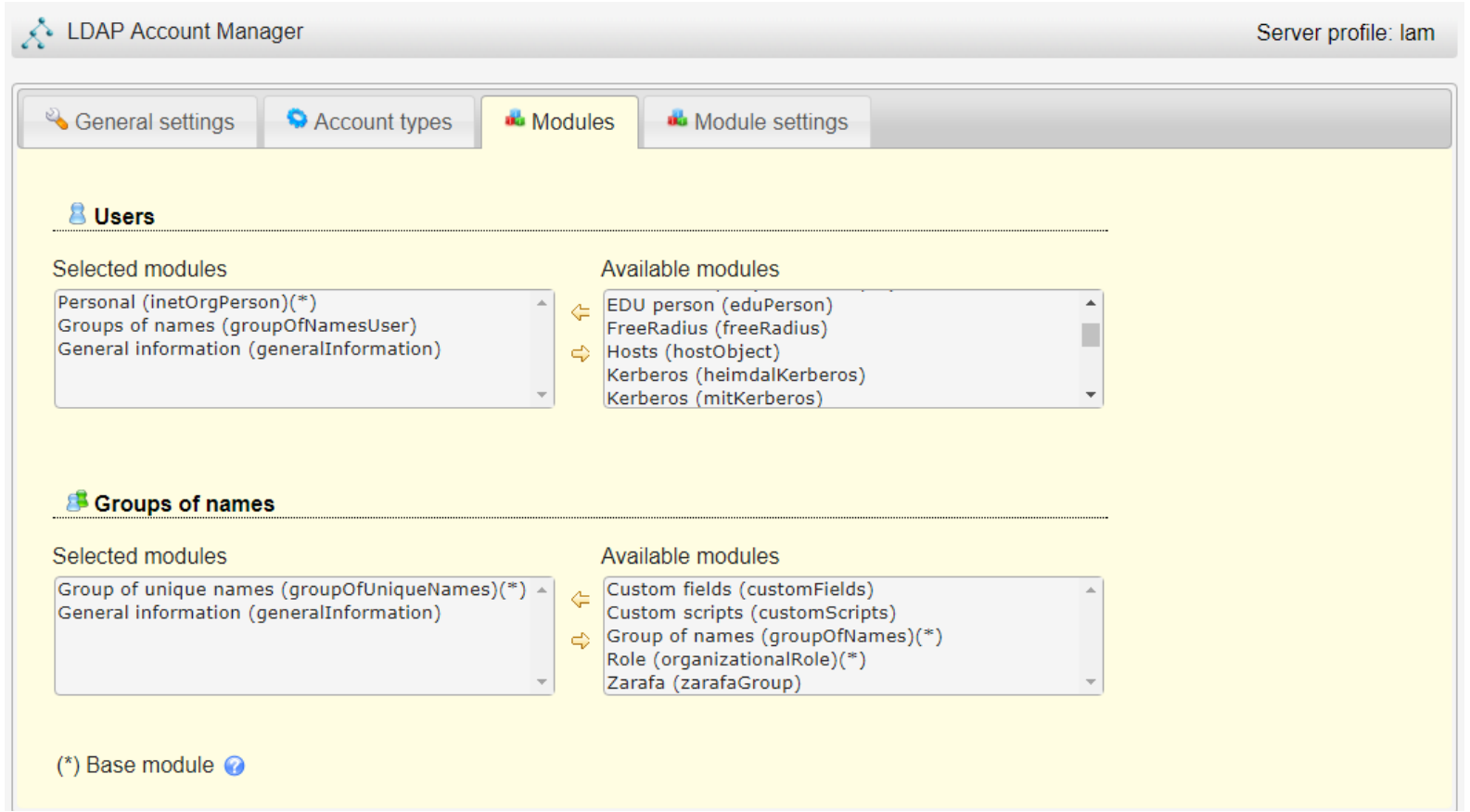

Fig.5. Display of connected modules

To implement a single sign-on page, the idea of which was that for the input to any resource or system of information and educational environment of the university user will be redirected to the single sign-on page to the environment (Fig.1). After successful 
authentication, the user selects the necessary resource (Fig.2) and enters without the need for re-entering the credentials (“LDAP Properties for CSVDE and VBScript”, 2017).

To realize this possibility was selected the CAS system (Central Authentication Service) (http://jasig.github.io/cas/4.0.x/index.html). This system is written using java servlets. Therefore, there was a need for Apache Tomcat to use it. The corresponding software has been installed on the server and configured to work with our LDAP database. There were also programmed forms for authentication in corporate colors and template decisions taken at the University:

- entry form;

- the form of a productive entry;

- the form of denial of entry.

In order to synchronize the University's corporate mail and available Google services with the LDAP database, we use the Google Apps Directory Sync program developed by Google (Oleksiuk, 2013). Currently not all features are used, but only synchronization of the structure and all users in Google Apps. As a result creating and editing users is one-time and only in the base LDAP. Next, as a result of synchronization, the corresponding accounts are created in the Google Apps environment.

\section{Google Apps Directory Sync}

\begin{tabular}{|c|c|}
\hline General Settings & - General Settings ? \\
\hline Google Apps Configuration & \multirow{11}{*}{$\begin{array}{l}\text { Choose what to synchronize } \\
\square \text { Organizational Units } \\
\square \text { Users Accounts } \\
\square \text { Groups } \\
\square \text { User Profiles } \\
\square \text { Shared Contacts } \\
\square \text { Calendar Resources }\end{array}$} \\
\hline LDAP Configuration & \\
\hline Org Units & \\
\hline User Accounts & \\
\hline Groups & \\
\hline User Profiles & \\
\hline Shared Contacts & \\
\hline Calendar Resources & \\
\hline Notifications & \\
\hline Logging & \\
\hline Sync & \\
\hline
\end{tabular}

Fig.6. View of Google Apps Directory Sync

The next task is to connect the user application user database to the LDAP:

- e-learning system http://e-learning.kubg.edu.ua;

- Wiki portal of the University http://wiki.kubg.edu.ua;

- scientific conferences and seminars http://conf.kubg.edu.ua;

- e-portfolio http://eportfolio.kubg.edu.ua;

- institutional repository http://elibrary.kubg.edu.ua; 
- base of master's works with the verification of plagiarism http://resbase.kubg.edu.ua;

- database of university registries http://rg.kubg.edu.ua and others.

Let us consider some of the connection.

The e-learning system is based on the Moodle platform, which already has an appropriate module for authenticating users through the LDAP database. This module should only be enabled and configured. To do this, you had to go through the link http://elearning.kubg.edu.ua/admin/auth_config.php?auth=ldap and fill out the specified elements of the form. Fragment shape configuration shown on (Fig.7).

LDAP server settings

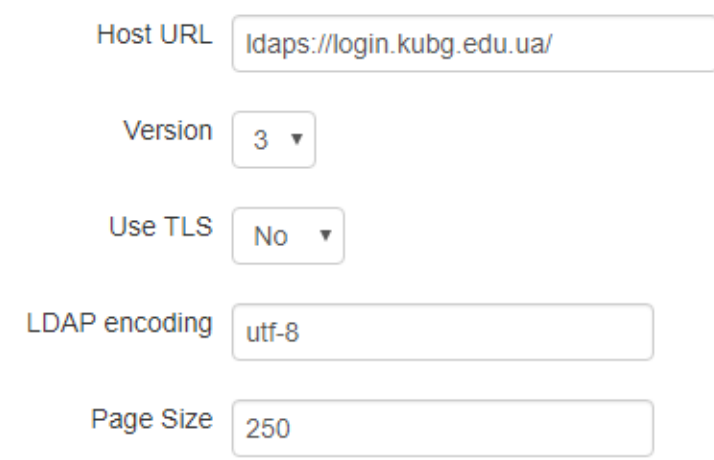

\section{Bind settings}

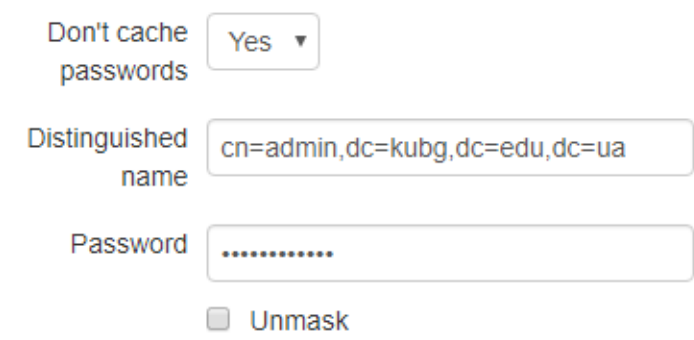

User lookup settings

User type Default

Fig.7. Fragment of the module configuration form

To synchronize groups from LDAP to the cohort, the local module local_ldap was installed in the Moodle system. Using it from the LDAP database to Moodle, the groups are transferred as cohorts and the necessary students are added to them. Thus, even placing students in groups is done only once in the LDAP database, and then only synchronized. 


\section{LDAP synching scripts}

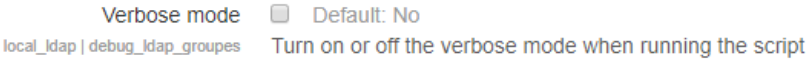

Synch Moodle's cohorts with LDAP groups

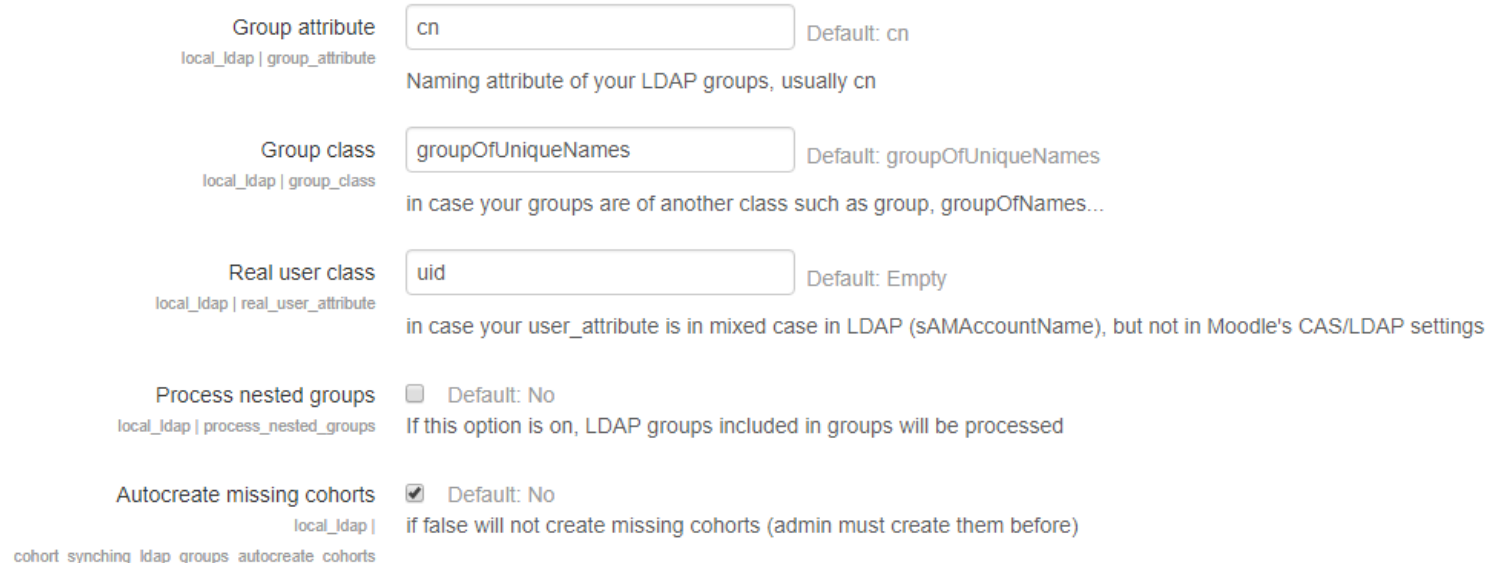

Fig.8. Fetch group sync setting

The Wiki University portal runs on the MediaWiki engine, which also includes the ability to authenticate through the LDAP database. To do this, the LDAP Authentication (LdapAuthentication) module was installed and connected and its settings specified in the LocalSettings.php file. Below is a listing of settings that apply to LDAP authentication.

\# LDAP authentification

require_once "\$IP/extensions/LdapAuthentication/LdapAuthentication.php";

\$wgAuth = new LdapAuthenticationPlugin();

$\$ w g L D A P D o m a i n N a m e s=\operatorname{array}($ 'kubgLDAP');

\$wgLDAPServerNames = array( 'kubgLDAP' => 'login.kubg.edu.ua');

$\$ w g L D A P S e a r c h A t t r i b u t e s=\operatorname{array}($ 'kubgLDAP' => 'uid');

$\$ w g L D A P U s e r B a s e D N s=\operatorname{array}\left(' k u b g L D A P^{\prime}=>\right.$ 'ou $=$ people, $\left.d c=k u b g, d c=e d u, d c=u a^{\prime}\right)$;

\$wgLDAPEncryptionType = array('kubgLDAP' => 'ssl');

$\$ w g L D A P P o r t=\operatorname{array}\left(' k u b g L D A P^{\prime}=>636,\right)$;

$\$ w g L D A P P r o x y A g e n t=\operatorname{array}\left(' k u b g L D A P^{\prime}=>\quad ' c n=a d m i n, d c=k u b g, d c=e d u, d c=u a^{\prime}\right)$;

\$wgLDAPProxyAgentPassword $=\operatorname{array}\left(' k u b g L D A P^{\prime}=>\right.$ '*************');

$\$ w g L D A P P a s s w o r d H a s h=\operatorname{array}\left(' k u b g L D A P^{\prime}=>\right.$ ' $\left.m d 5 '\right)$;

\$wgLDAPPreferences $=\operatorname{array}\left(' k u b g L D A P^{\prime}=>\right.$ array( 'email' $=>$ 'mail','realname' =>

'cn','nickname' => 'uid','language' => 'preferredlanguage'));

\$wgMinimalPasswordLength $=1$;

To save previous accounts, local authentication is allowed along with LDAP authentication. But the detected duplicate accounts can be merged into one. These minor technical changes may be made by an administrator or employee with the appropriate rights. Fig. 9 shows the login form with the domain selection - for the login with the LDAP account you must select "login.kubg.edu.ua”. 
Special page

\section{Login to the system}

You must activate coockies to enter Borys Grinchenko Kyiv University

Home page

New edits

Random article

$\checkmark$ Tools

Special pages

Print version

- To share

\section{User name}

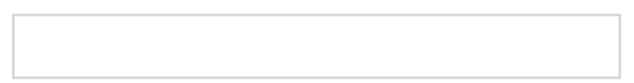

Password

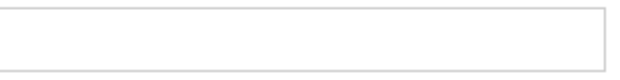

Your domain:

login.kubg.edu.ua $\mathbf{v}$

Remember me

\section{Enter}

Help with logging into the system

Fig.8. University entrance page to the Wiki

The system of scientific conferences and seminars is based on the open conference system engine, which also includes a module for LDAP authentication (Halatenko, 2017). But the specificity of this module is that the user must fill in the registration form in any case, indicating in it the same data that it has in the LDAP database. This approach is not very userfriendly. Therefore, reprogramming of the LDAP authentication module was implemented. All changes affected only one file.

LDAP authentication is set alongside (without exception) standard registration and authentication in the system itself. Figure 9 shows the LDAP authentication configuration form.

As a result, users who have an account in the LDAP database log in using their login and password. External users are able to register in the system as before. 


\section{Authentication Sources}

Заголовок

Опції

\section{LDAP}

Enable user profile synchronization (if supported by this authentication $\mathrm{p}$ logs in, and profile changes (including password changes) made within $\mathrm{O}$ information will be kept separate from remote source profile information. Enable user password modification (if supported by this authentication pl OCS "lost password" feature to reset a forgotten password. These functic Enable user creation (if supported by this authentication plug-in). Users । authentication source if they do not already exist. Additionally, if this sol added to the remote authentication source.

\section{LDAP Settings \\ Server hostname \\ Server port \\ Base DN \\ Manager DN \\ Account name attribute \\ Manager password \\ Password encryption

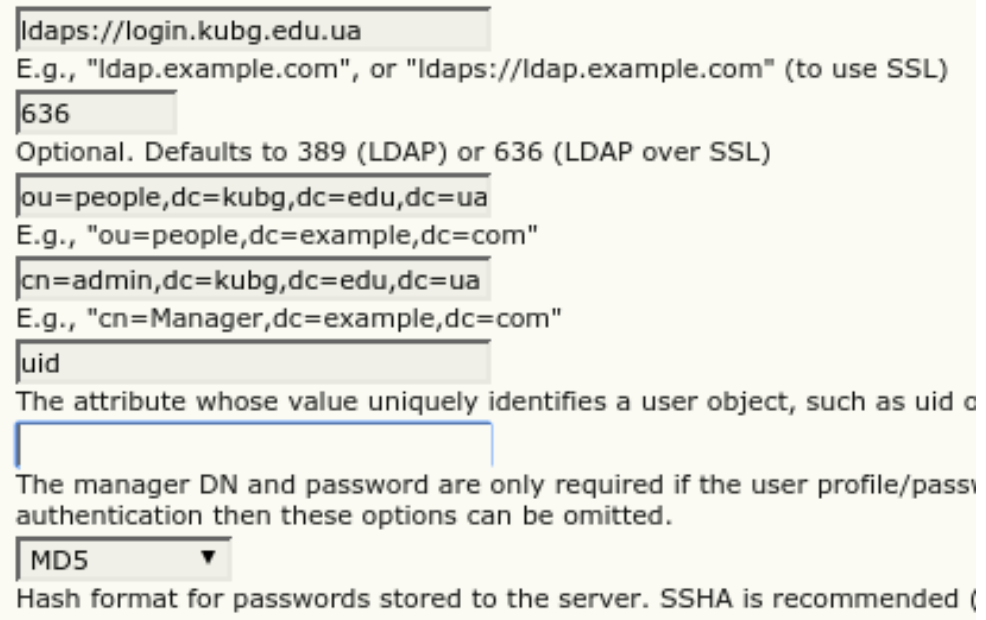

Fig.9. LDAP Authentication Configuration Form

In general, the integration of educational electronic resources into a single information and educational environment is very important for the university, since:

- the single entry point for all resources and systems is used;

- authentication of all university users and configuration management is provided;

- there is coordination of functions and data exchange between components of the eenvironment;

- a single approach to data storage and high speed access to them is carried out;

- enhanced protection of information from unauthorized access.

\section{REFERENCES}

Authentication Plugins (2017). Retrieved June 10, 2017

https://wiki.duraspace.org/display/DSDOC3x/Authentication+Plugins.

Centralized authentication using OpenLDAP (2017). June 10, 2017

https://wiki.gentoo.org/wiki/Centralized_authentication_using_OpenLDAP

Community developed LDAP software (2017). June 10, 2017

http://www.openldap.org/

LDAP Properties for CSVDE and VBScript (2017). June 10, 2017

http://www.computerperformance.co.uk/Logon/LDAP_attributes_active_directory.htm 
Morze, N., Buinytska, O. (2015) Open e-environment - the key instrument of the education quality. International Journal of Research in E-learning, 1 (1), 25-47. ISSN 24512583

Ogneviuk, V., Klymenko, N., Levitas, F., Movchun, A., Zhyltsov, O., Bezpalko, O., Morze, N., Varchenko-Trotsenko, L. \& Buinytska, O. (2016). I am a student. (6th ed.). Kyiv: Borys Grinchenko Kyiv University.

Halatenko, V. (2017). Identification and authentication, access control. June 10, 2017 http://citforum.ru/security/articles/galatenko/. (in Russian)

Oleksiuk, V. (2013). Google Apps Cloud Services Integration Experience in Higher Education Institutions' Information and Education. Information technology and learning tools, 3 (35), 64-73. June 10, 2017

http://journal.iitta.gov.ua/index.php/itlt/article/view/824/631. (in Ukrainian)

Oleksiuk, V. (2012). A unified authentication system as a step towards creating the educational space of a general education institution. Scientific journal of National Pedagogical Dragomanov University. Series 2, Computer-based learning systems, 13 (20), 188-193. (in Ukrainian)

Panov, D. (2017). LDAP - Universal catalogs at the service of companies. Computer Review, IT for Business. June 10, 2017, http://ko.com.ua/ldap_universalnye_katalogi_na_sluzhbe_kompanij_49489. (in Russian)

Spivakovskyi, O. (2014). Construction of ICT infrastructure of universities: problems and solutions. Information technology and learning tools, 1 (39), 99-116. June 10, 2017 http://journal.iitta.gov.ua/index.php/itlt/article/view/996\#.Uzz8sfl_t1Z. (in Ukrainian) 